\title{
Breast internal dose measurements in a physical thoracic phantom
}

Avaliação da dose interna mamária em um phantom físico de tórax

\author{
S. D. Silva ${ }^{1 *}$; M. A. Oliveira ${ }^{2}$; A. L. S. Castro ${ }^{1}$; H. G. Dias ${ }^{2}$; L. B. Nogueira ${ }^{3}$; T. \\ P. R. Campos ${ }^{1}$ \\ ${ }^{l}$ Nuclear Engineering Department, Federal University of Minas Gerais, 31270-90, Belo Horizonte - Minas Gerais, \\ Brazil \\ ${ }^{2}$ Departament of Oncology, Clinics Hospital of Uberlândia, 38405-320, Uberlândia - Minas Gerais, Brazil \\ ${ }^{3}$ Anatomy and Imaging Department, Federal University of Minas Gerais, 30130-100, Belo Horizonte - Minas \\ Gerais, Brazil
}

*sadonatosilva@hotmail.com

(Recebido em 20 de julho de 2016; aceito em 23 de fevereiro de 2017)

\begin{abstract}
Radiotherapy is a cancer treatment intended to deposit the entire prescribed dose homogeneously into a target volume in order to eliminate the tumor and to spare the surrounding healthy tissues. This paper aimed to provide a dosimetric comparison between the treatment planning system (TPS) ECLIPSE from Varian Medical Systems and the internal dosimetric measurements in a breast phantom. The methodology consisted in performing a 3D conformal radiotherapy planning with two tangential opposite parallel fields applied to the synthetic breast in a thoracic phantom. The irradiation was reproduced in the Varian Linear accelerator, model SL - 20 Precise, 6 MV energy. EBT2 Radiochromic films, placed into the glandular equivalent tissue of the breast, were used to measure the spatial dose distribution. The absorbed dose was compared to those values predicted by the treatment planning system; besides, the dosimetric uncertainties were analyzed. The modal absorbed dose was in agreement with the prescribed value of $180 \mathrm{cGy}$, although few high dose points between 180 and $220 \mathrm{cGy}$ were detected. The findings suggested a non-uniform dose distribution in the glandular tissue of the synthetic breast, similar to those found in the TPS, associated with the irregular anatomic breast shape and presence of inhomogeneities next to the thoracic wall generated by the low lung density.

Keywords: Radiotherapy, Film Dosimetry; Thoracic Phantom
\end{abstract}

A radioterapia é um tratamento de câncer que visa depositar toda a dose prescrita de forma homogênea no volume alvo, a fim de eliminar o tumor, poupando tecidos sadios adjacente. Este trabalho teve como objetivo fornecer uma comparação dosimétrica entre o sistema de planejamento (TPS) ECLIPSE da Varian Medical Systems e medidas dosimétricas internas realizadas em um phantom de mama. A metodologia consistiu em realizar um planejamento radioterápico conformacional 3D com dois campos paralelos opostos tangenciais aplicados em uma mama sintética de um phantom torácico. A irradiação foi efetuada no acelerador linear da Varian, modelo SL - 20 Precise, com 6 MV de energia. Filmes radiocrômicos EBT2 posicionados no interior do tecido equivalente glandular mamário do phantom foram utilizados para mensurar a distribuição espacial dosimétrica. A distribuição da dose foi comparada com a dose prescrita no TPS e as incertezas foram analisadas. A dose absorvida modal ficou de acordo com o valor prescrito no TPS de 180 cGy, embora tenham sido encontrados poucos pontos de altas doses no intervalo de 180 a 220 cGy . Os resultados sugerem uma distribuição de dose não uniforme no tecido glandular da mama sintética, similar aos valores encontrados no TPS, relacionados à anatomia irregular da mama e a presença de não homogeneidades na parede torácica gerada pela baixa densidade do pulmão.

Palavras Chave: Radioterapia, Dosimetria de Filmes, Phantom Torácico

\section{INTRODUCTION}

According to the World Health Organization [1], breast cancer is the main cause of death of women by cancer worldwide. However, a good prognosis is enhanced if it is associated with early detection and proper treatment [2]. Radiotherapy is one of the therapeutic modalities for the treatment of this neoplasm [3]. This modality employs ionizing radiations in the treatment of 
patients with a malignant neoplasm and occasionally benign diseases. "The aim of radiotherapy is to deliver a precisely measured dose of irradiation to a defined volume with as minimal damage as possible to surrounding healthy tissue, resulting in eradication of the tumor, high quality of life, and prolongation of survival at competitive cost" [4].

The principal challenge of radiotherapy is to deposit the entire prescribed dose in the target volume homogeneously, sparing the surrounding tissue. Due to the anatomy of the chest wall, breast radiotherapy is particularly challenging because it is quite difficult to achieve a homogeneous prescribed dose over the glandular tissue. In addition, there are organs at risk in their neighborhoods, such as the lungs, heart and the contralateral breast. Indeed, those organs should receive doses as low as possible to avoid early and late complications [5].

The measurements of the absorbed dose by the breast and the surrounding organs are of paramount importance in breast radiotherapy. The knowledge of the internal doses shall be a requirement for dosimetric validation of the radiation treatment planning in order to confirm the calculated dose distribution. Physical simulators can assist this validation process. Anthropomorphic and anthropometric phantoms composed of materials that simulate the absorption and scattering of radiation became important tools in radiotherapy verification process [6].

Concerning the dosimetric measurements, radiochromic films have also been employed to provide a map of the spatial dose in experimental protocols. Such films have an equivalent tissue composition in which an enclosed organic compound changes its color according to the radiation dose received [7]. The gafchromic EBT2 film is an inexpensive tool compared to ionization chambers and thermoluminescent dosimeters. It was designed to be used in dosimetry applied to radiotherapy and diagnostic radiology. The EBT2 film, developed by International Specialty Product (ISP), can be used in most radiotherapy existing technologies, and the films are suitable for measuring a wide dose range from $1 \mathrm{cGy}$ to $40 \mathrm{~Gy}$ [7]. In order to achieve its proper use, the EBT2 films as other relative detectors must be calibrated. This process allows finding the relation between the absorbed dose imparted in the film and its optical density. This mathematical relation can be plotted generating a calibration curve [8].

The aim of this paper was to reproduce two opposite parallel fields used in the breast radiotherapy in a thoracic phantom in order to evaluate the spatial dose distribution and compare to the absorbed dose and isodoses curves predicted by the treatment planning system (TPS).

\section{MATERIAL AND METHODS}

\subsection{Thoracic phantom and CT imaging}

The phantom used in this experiment was previously developed by the research group Nucleo de Radiações Ionizantes - NRI/CNPq [9-11]. This phantom presents metric shapes and chemical compositions similar to a human body, based on the ICRU report No. 44 [6]. The CT images were performed by the Hispeed CT, GE Healthcare's with exposure factors of $120 \mathrm{kV}$ and a current of $80 \mathrm{~mA}$, corresponding to a routine thorax CT. The total area scanned was $184.5 \mathrm{~cm}^{2}$, with slices of $2.0 \mathrm{~mm}$ thick, totalizing 91 slices, saved in Digital Imaging and Communications in Medicine (DICOM) format [11].

\subsection{EBT2 film calibration}

A group of ten EBT2 film segments $\left(3.0 \times 3.0 \mathrm{~cm}^{2}\right)$ was irradiated in a $6 \mathrm{MV}$ linear accelerator, Varian SL - Precise 20. The calibration procedure was performed in a water phantom with external dimensions of $40 \times 40 \times 40 \mathrm{~cm}^{3}$. An adjustable support with horizontal brackets of $5.0 \times 5.0 \times 100$ $\mathrm{mm}^{3}$ with longitudinal separation of $2.0 \mathrm{~cm}$ was placed in the box. Those brackets held the film pieces during the process of calibration at the central axis of the box. The films were placed at depths of 9.5 and $19.5 \mathrm{~cm}$. A $10 \times 10 \mathrm{~cm}^{2}$ field was applied with a source surface distance (SSD) of $100 \mathrm{~cm}$. The films were manipulated only during irradiation and readout procedures otherwise. Those were kept in the dark to minimize the effects of ambient light. The absorbed doses 
measured by the radiochromic films at the depths of $9.5 \mathrm{~cm}$ and $19.5 \mathrm{~cm}$ were calculated by multiplying the monitor units by the percentage depth dose. The dose encompassed 0 to 499.7 cGy in order to properly evaluate the shape of the calibration curve.

\subsection{Digitization and treatment of the calibration data}

The exposed radiochromic films were scanned by an HP Scanjet G4050 model, operating in transmission mode. The films were scanned $24 \mathrm{~h}$ after their exposures to complete their selfdevelopment. The scanner was warmed-up for one hour in order to stabilize its temperature before proceeding with the film's reading. In addition, the digitization of blank, unexposed and overexposed gafchromic EBT2 films were performed five times. Those procedures were executed in order to prevent possible noise, artifacts and correct defective pixels. Defective pixels were defined "as pixels that differ in intensity from the blank (unattenuated) signal, which is equal to 216", as suggested by Devic et. al. [12,13] and Thompson et al. [14]. All the films were scanned as slide-type, using the following settings: 300 pixels per inch in RGB mode with 48 bits, 16 bits per color saved in TIFF format. The calibration films were digitized together, placed at the center of the scanner, as well as the films used in the phantom's irradiation. After the scanning procedure, the digitized images were separated into RGB channels using the ImageJ software [15]. The RGB value of each component was settled into a range from 0 to 255 . Since the absorbance spectra of the active component of the gafchromic EBT2 have a peak at $636 \mathrm{~nm}$, the films have their sensitivity maximized by measurements on the red color channel [7].

The mean intensity of each irradiated film was measured in the red color channel with ROIs of $2.0 \mathrm{~cm}^{2}$, avoiding the edges of the image. Then, the optical density (OD) was associated with the absorbed dose, following Equation 1, in which the optical density was defined [12, 16], as:

$$
O D=\log _{10}\left(I_{0} / I\right),
$$

in which $I_{0}$ is the R intensity from RGB digital image of the non-irradiated film, and $I$ is the R intensity of the irradiated film $[12,16]$. The standard deviations of the optical densities of the exposed and unexposed films were calculated as described by Devic et al. [12, 13] as follows:

$$
\sigma(O . D)=\frac{1}{\ln _{10}} \sqrt{\frac{\sigma(\text { unexposed })^{2}+\sigma(\text { overexposed })^{2}}{\text { OD(unexposed })^{2}-O D(\text { overexposed })^{2}}+\frac{\sigma(\text { irradiated })^{2}+\sigma(\text { overexposed })^{2}}{O D(\text { irradiated })^{2}-O D(\text { overexposed })^{2}}}
$$

in which $\mathrm{OD}$ (unexposed) and $\sigma$ (unexposed) are the average and the standard deviation of the unexposed film, $\mathrm{OD}$ (overexposed) and $\sigma$ (overexposed) are the average and the standard deviation of the overexposed radiographic film, and OD(irradiated) and $\sigma$ (irradiated) are the average and the standard deviation of the irradiated film's in the red component $[12,13,14]$. The background value is the zero-light intensity transmitted, determined over the ROI with an overexposed radiographic film (opaque film). After evaluating the dose and the optical density of the ten calibration films, a calibration curve was fitted according to Devic et al. [12]. The following mathematical function was applied:

$$
D_{f i t}=a+b . O D+c . O D^{n}
$$

in which $a, b$ and $c$ are the fitting parameters of the curve, $O D$ is the optical density and $n$ is the power index of the equation. 


\subsection{Treatment planning system and phantom irradiation}

The Eclipse software from Varian Medical Systems was used to carry out the calculation. The 3D conformal radiotherapy planning was based on the protocol suggested by the radiation oncology group, using the phantom's Computed Tomography (CT) images previously generated. Two opposite parallel tangential fields were used. The glandular tissue of the left breast was delineated as the planned target volume (PTV). A prescribed dose of $180 \mathrm{cGy}$ was defined at the isocenter with a normalized value of $100 \%$. Then, the radiochromic films were cut into dimensions compatible with the anatomy of the breast phantom and partially inserted into the thoracic phantom as follows: i) film 1 between the upper outer quadrant and upper inner quadrant, ii) film 2, between lower outer quadrant and inner lower quadrant; and, film 3 between internal quadrants. The three films received the single fraction dose of $180 \mathrm{cGy}$ prescribed to PTV (Figure 1).

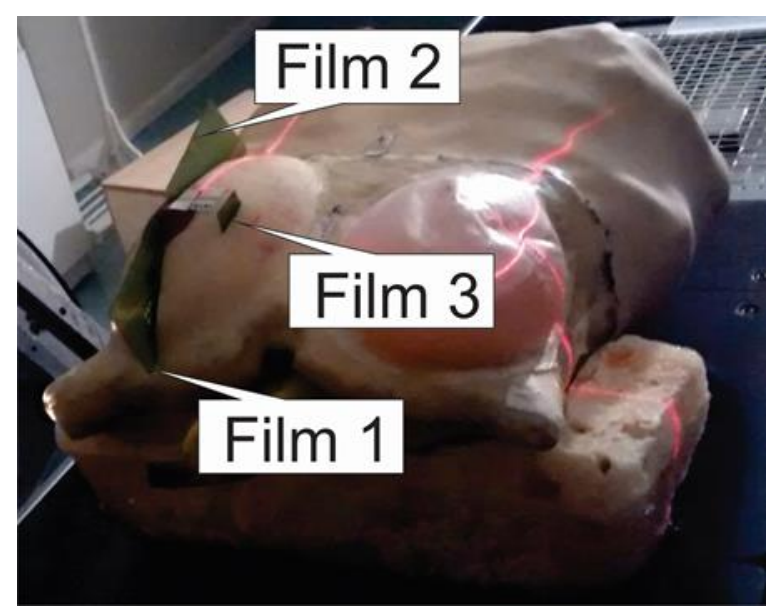

Figure 1: Films positioning on thoracic phantom

The tangent internal field used the following parameters: Source-Axis Distance (SAD) of 100.0 $\mathrm{cm}$; Calculated Source-Skin-Distance (SSD) of $95.1 \mathrm{~cm}$; Field size: $16.0 \mathrm{~cm}$ x $8.0 \mathrm{~cm}$ (X1:$8.0 \mathrm{~cm}, \mathrm{X} 2:+8.0 \mathrm{~cm}, \mathrm{Y} 1:-5.0 \mathrm{~cm}, \mathrm{Y} 2:+3.0 \mathrm{~cm})$; Gantry rotation $295.0^{\circ}$; Collimator rotation $100.0^{\circ}$; Isocenter position X: $8.0 \mathrm{~cm}, \mathrm{Y}:-7.4 \mathrm{~cm}, \mathrm{Z}: 2.3 \mathrm{~cm}$; Field weight factor: 0.500; Wedge: $1 \mathrm{MW}$ angle of $60^{\circ}$, motorized wedge weight factor 0.300; monitor unit (UM) of 104.7 MU.

Concerning the tangent external field, the following parameters used were: Source-Axis Distance (SAD) of $100.0 \mathrm{~cm}$; Calculated Source-Skin-Distance (SSD) of $93.8 \mathrm{~cm}$; Field size: 16. $0 \mathrm{~cm}$ x $8.0 \mathrm{~cm}(\mathrm{X} 1:-8.0 \mathrm{~cm}, \mathrm{X} 2:+8.0 \mathrm{~cm}, \mathrm{Y} 1:-5.0 \mathrm{~cm}, \mathrm{Y} 2:+3.0 \mathrm{~cm})$; Gantry rotation $115.0^{\circ}$; Collimator rotation $260.0^{\circ}$; Isocenter position X: $8.0 \mathrm{~cm}, \mathrm{Y}:-7.4 \mathrm{~cm}, \mathrm{Z}: 2.3 \mathrm{~cm}$; Field weight factor: 0.500; Wedge: $1 \mathrm{MW}$ angle of $60^{\circ}$, motorized wedge weight factor 0.300 ; monitor unit (UM) of 108.4 MU. In both fields the Anisotropic Analytical Algorithm (AAA) for heterogeneity correction was applied.

\subsection{Evaluation of uncertainty of the measured dose}

The uncertainty assigned to the dose measured with the EBT2 lot: \# F 10070902B was estimated. Error propagation, as described in the Guide to the Expression of the Uncertainty in Measurement (GUM), was used for estimation of all those components that had expanded uncertainty with a 95\% confidence level and a coverage factor $(\mathrm{k}=2)$ [17].

The uncertainty regarding the calibration curve was calculated according to Sou-Tung ChiuTsaoa and Maria F. Chan (2009) [18]. The equation 4 takes into account the uncertainties in the measured $O D$ and the uncertainties in the fitting procedure of the calibration curve, as follows: 


$$
\sigma_{D, f i t}=\frac{u_{a}^{2}+(O D)^{2} u_{b}^{2}+(O D)^{6} u_{c}^{2}}{D_{f i t}}
$$

in which $u a, u b$ e $u c$ are respectively the uncertainties of the fitting curve parameters $a, b$ and c,; $D f i t$ is the fitted dose value calculated using the fitting function in Eq. (3); and, $O D$ is the optical density. All these parameters were extracted from the calibration curve.

\section{RESULTS}

\subsection{Film calibration curve}

The fitting coefficients of the polynomial function determined by the Origin software were $\mathrm{a}=$ $-21.62276, b=683.56017, c=4117.23372$ with the standard errors, respectively, of 1.579 , 42.71322 and 384.09088 [19]. The coefficient of determination $\mathrm{R}^{2}$ was equal to 0.9953 . The adjustment provided the coefficients of the Eq.3 that relates the absorbed dose to the optical density of the calibration films. Figure 2 presents the calibration curve. The value found for $n$ was 2.5 .

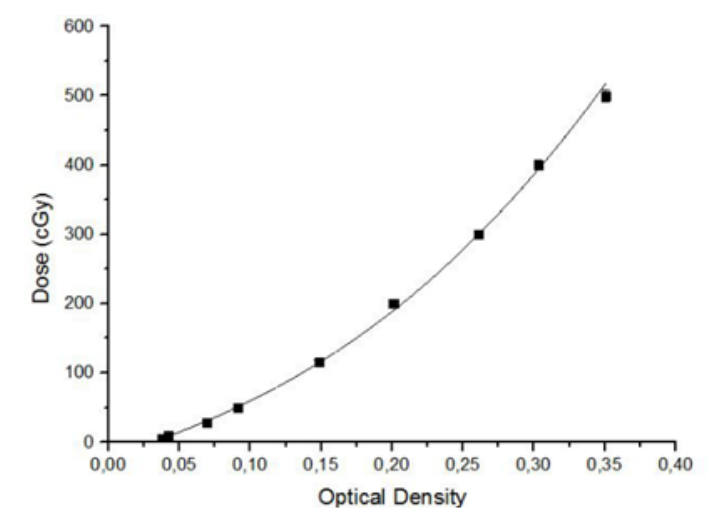

Figure 2: Calibration curve for EBT2 Films exposed to the $6 \mathrm{MV}$ photon beam. The square symbols were for the OD data from individual calibration films. The solid line was for the fitted polynomial function.

\subsection{Dosimetric analysis}

The Eclipse planning system has exhibited a uniform dose distribution across the glandular breast tissue, as depicted in Figure 3. The maximum dose found was $106.5 \%$ of the prescribed dose (Figure 3). 

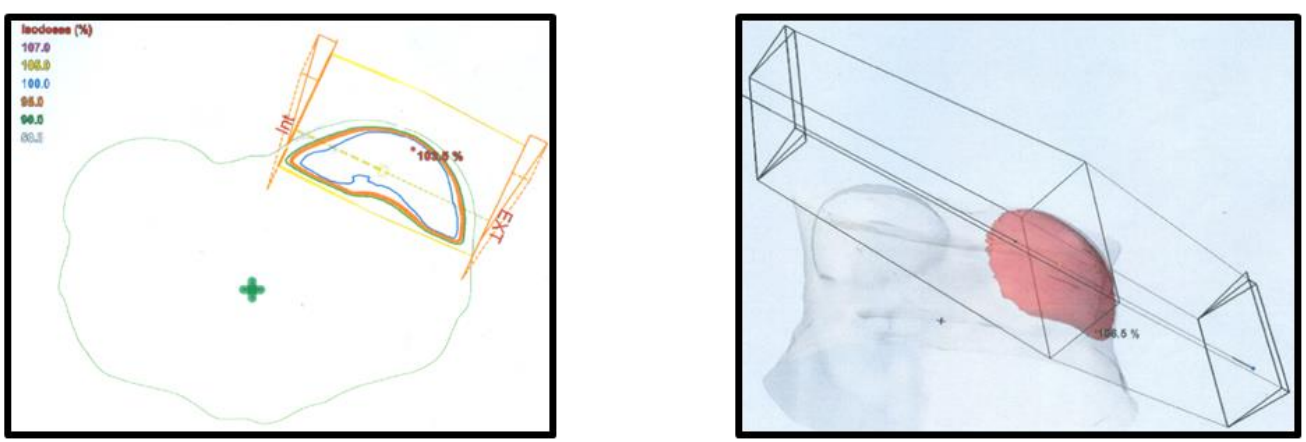

Figure 3: Eclipse dosimetric distribution and a 3D planning reconstruction showing the maximum dose provided.

The radiochromic films placed inside the breast were evaluated. The optical densities were converted to absorbed dose and the spatial dose distributions were depicted in Figure 4.

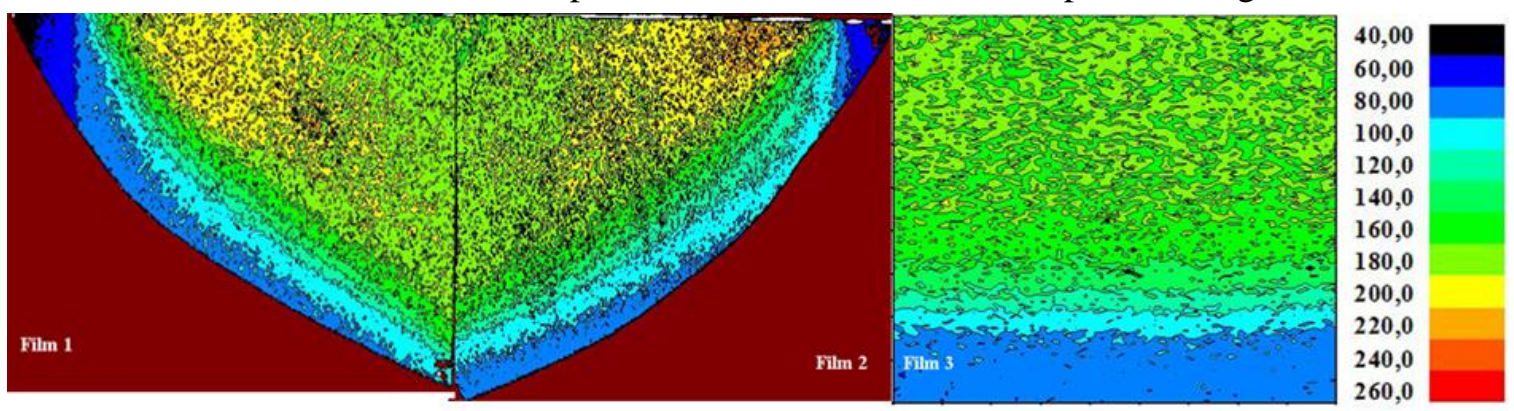

Figure 4: EBT2 spatial dose distribution measured on the red component on film 1, 2 and 3 in units of $c G y$.

\subsection{Uncertainty of the measured dose}

Table 1 shows the uncertainty analysis of the experiment. The overall uncertainty of the experiment was $4.7 \%$. All possible sources of uncertainty and their types were specified in table 1 , followed by their values in percentage and the evaluation of their standard uncertainty. The combined standard uncertainty and the expanded uncertainty were also presented. 
Table 1: Absorbed dose overall uncertainty at $95 \%$ confidence interval

\begin{tabular}{|c|c|c|c|}
\hline Sources of uncertainty & $\begin{array}{l}\text { Value } \\
(\%)\end{array}$ & $\begin{array}{c}\text { Standard } \\
\text { Uncertainty }\left(u_{i}\right)\end{array}$ & Type \\
\hline Ion chamber calibration $^{1}$ & 1.6 & 0.9 & $\mathrm{~B}$ \\
\hline $\mathrm{SDD}^{1}$ & 2.0 & 1.2 & B \\
\hline Influence of the ROI size ${ }^{2}$ & 0.5 & 0.2 & A \\
\hline Film positioning in the calibration $(9.5 \mathrm{~cm})$ & 0.8 & 0.5 & $\mathrm{~B}$ \\
\hline Film positioning in the calibration $(19.5 \mathrm{~cm})$ & 0.7 & 0.4 & $\mathrm{~B}$ \\
\hline Phantom positioning to $951 \mathrm{~mm}$ & 0.8 & 0.5 & B \\
\hline Phantom positioning to $939 \mathrm{~mm}$ & 0.9 & 0.5 & B \\
\hline Film Uniformity ${ }^{2}$ & 1.7 & 0.6 & A \\
\hline Film Resolution ${ }^{2}$ & 0.5 & 0.3 & B \\
\hline Scanner Uniformity $^{2}$ & 1.6 & 0.6 & A \\
\hline Scanner Resolution ${ }^{2}$ & 2.0 & 0.6 & A \\
\hline Linac Calibration procedure & 2.0 & 1.2 & B \\
\hline \multicolumn{4}{|l|}{ Uncertainty $\sigma\left(D_{f i t}\right)$ in the fitted dose value } \\
\hline using the $\mathrm{e}^{3}$ fitting function of the calibration & 0.4 & 0.1 & A \\
\hline \multicolumn{4}{|l|}{ curve } \\
\hline Combined Standard Uncertainty $\left(u_{c}\right)=$ & & & 2.4 \\
\hline Expanded Uncertainty $(U)$ & & & 4.7 \\
\hline
\end{tabular}

${ }^{1,2}$ References: ${ }^{1}$ Khan [23]; ${ }^{2}$ Huet et al., [25] and ${ }^{3}$ Chiu-Tsao and Chan [18].

\section{DISCUSSION}

\subsection{Film calibration curve}

As mentioned earlier, the calibration films were placed on water. According to the manufacturer, the EBT2 radiochromic film can be used in water for short periods without permanent damage [20, 21]. Aldelaijan et al. (2010) [22] conducted a study aiming to demonstrate the impact of the measures taken with the radiochromic EBT2 film submerged in water. The authors of this study concluded that the water affects the response of the film to radiation only if the films were immersed for a long period, besides changes in the optical density of the film due 
to immersion in water are negligible for periods shorter than 30 minutes. In this experiment, each piece of film remained submerged for less than five minutes. Therefore, no alteration was observed in the submerged calibration films.

\subsection{Dosimetric analysis}

The radiotherapy planning was performed in order to deliver the most homogeneous dose as possible in the target volume defined on the TPS, with a prescribed dose value of $180 \mathrm{cGy}$ at the isocenter. Figure 4 shows a representation of the film in full size with an absorbed dose ranging from $60 \mathrm{cGy}$ to $220 \mathrm{cGy}$. The part of the film inserted into the glandular tissue received doses ranging from $160 \mathrm{cGy}$ up to $220 \mathrm{cGy}$. Dose points higher than $260 \mathrm{cGy}$ were also observed. The region placed out of the tissue registered absorbed doses of $40 \mathrm{cGy}$ up to $160 \mathrm{cGy}$. Borges et al. (2014) [5] qualified the breast radiotherapy as particularly challenging because the anatomy of the chest wall surrounded by organs at risk implies difficulty in attaining a full homogeneous dose at the glandular breast tissue sparing the heart and lungs. This was confirmed in this paper by the results of the spatial dose distribution found in the films at the synthetic breast.

Portions of the films placed outside the phantom presented lower doses. This effect can be explained by the build-up effect, in which high-energy beams exhibit the maximum dose in a point deeper into the tissue, or in this case into the phantom. The region between the surface and the point of maximum dose is called a dose build-up region. This effect is clinically known as the skin-sparing effect. For high voltage beam, a dose on the surface is much lower than the maximum level in the tissue, which is a beneficial effect in situations where the tumor is not superficial. Indeed, it spares the skin surface of the patient [23].

The films $\mathrm{n}^{\circ} 1$ and $\mathrm{n}^{\circ} 2$ have presented high dose points, with values superior to $260 \mathrm{cGy}$. Butson et al. (2003) [16] describes that microscopic and macroscopic changes may occur in the uniformity of the film due to several factors. Microscopic variations on the active compound of the film can affect the spatial resolution. This is a determining factor whether exhibiting or not the non-uniformity of the data. For example, at high spatial resolutions, defective points that would not be noted at the low resolutions end up being evident. This effect in our experiment may have caused the expression of some of the high dose points at the film. Devic et al. (2005) [13] recommend applying a correction in these "bad" pixels. Thompson and Campos (2013) [14] have chosen to present these points in their work and discuss them. Therefore, such high dose points may not be related to the irradiation performed in the phantom.

Concerning the comparison of the dose values from TPS and those obtained through EBT2 spatial dose distribution, taking into account the experimental uncertainty, the experimental measurements attend the absorbed dose predicted by the TPS; however, remarkable heterogeneity was observed. Table 2 shows the mean with its uncertainty value, modal and median experimental values that are in agreement with the TPS.

The absorbed doses on film 3 registered low values due to its position in the breast phantom. Most of the film 3 was positioned out of the breast tissue. The film was in the build-up region where there was a lack of electronic equilibrium.

In this work, a dosimetric comparison between the treatment planning system and absorbed dose profiles measured using radiochromic films in a phantom was performed. Dose values were found in the range of $180 \mathrm{cGy}$ to $220 \mathrm{cGy}$. It is noteworthy, that such experimental data are in agreement with those found by Nogueira et al. (2015) [24]. 
Table 2: Mean, modal and median dose values of the EBT2 spatial dose distribution measured in this research in $c G y$.

\begin{tabular}{cccc}
\hline Film & Mean & Modal & Median \\
\hline Film 1 & $180 \pm 8$ & 176 & 171 \\
Film 2 & $178 \pm 8$ & 176 & 176 \\
Film 3 & $153 \pm 7$ & 158 & 158 \\
\hline
\end{tabular}

\subsection{Uncertainty of the dose measurements}

The uncertainties due to the film and digitized procedures (uniformity, resolution) were estimated following recommendations of Huet et al. (2012) [25]; while the uncertainties due to dose fitting function from the calibration procedure were evaluated according to Chiu and ChanTsao (2009) [18]. The methods had been thoroughly explained on the references, dismissing further explanation here. The uncertainties due to ionization chamber calibration and SSD were obtained from Khan (2003) [23].

It is noteworthy that the film measurements in the two depths simultaneously aimed to optimize the calibration process since the experiment disrupted the radiation therapy routine at the hospital. However, uncertainty related to film positioning in the calibration procedure based on two positions (Table 1) demonstrated to have a few influences on the overall dose measurement uncertainty.

The TPS was performed with the recommended value of $180 \mathrm{cGy}$. The maximum value found in the breast was $106.5 \%$. The maximum value estimated by TPS was $191.7 \mathrm{cGy}$. However, the experimental values reproduced a maximum value higher than the data provided by the planning system. Further investigation shall be performed to better explain the high dose points. These findings demonstrate the relevance of performing dosimetric measurements on a phantom.

\section{CONCLUSION}

The knowledge of the internal breast absorbed doses is a suitable requirement to validate the breast radiation therapy planning. In this work, absorbed doses in the breast were obtained by the EBT2 films in order to compare the treatment planning suggested by the radiation oncology group of the hospital. The results showed that homogeneous spatial dose distribution in the breast is difficult to achieve due to the irregular anatomic breast shape and the presence of tissue-interface effects at the lung surface, generated by the lack of electronic equilibrium. The absorbed doses in the breast varied between 160 and 220 cGy in the overall distribution. The under dosage are correlated to the build-up region. The high-dose points may be caused by the differences in the non-uniformity of the film composition. However, the modal dose was in accordance with the prescribed dose. The absorbed dose in the glandular breast reached the prescribed dose of 180 cGy at $100 \%$ isodoses, considering the experimental uncertainty. The present measurements provided relevant dosimetry to improve breast radiation therapy.

\section{ACKNOWLEDGEMENTS}

The authors are grateful to Conselho Nacional de Pesquisa (CNPq) by the process 456719 / 2013-0 REBRAT-SUS project and Comissão de Aperfeiçoamento de Pessoal do Nível Superior (CAPES) for the financial support, and to the Programa de Pós-graduação em Ciências e Técnicas Nucleares da Universidade Federal de Minas Gerais (PCTN-UFMG) and the Núcleo 
de Radiações Ionizantes (NRI-CNPq). The authors are also thankful to Departmento de Oncologia / Hospital das Clínicas de Uberlândia due to contributions.

\section{REFERENCES}

1. World health organization. Women's health - WHO. 2015. Available at: http://www.who.int/mediacentre/factsheets/fs334/en/. Accessed 19 May 2015.

2. INCA. Instituto Nacional de Câncer, Brasil. Controle de Câncer de Mama: Documento de Consenso. Rio de Janeiro : INCA; 2004.

3. Scaff L. Física na Radioterapia: A base analógica de uma era digital. Editora Projeto Saber, São Paulo - Brasil, V.2. 2010.

4. Halperin EC, Perez CA, Brady LW (eds) Principles and Practice of Radiation Oncology, Fifth Ed. Pa: Lippincott Williams \& Wilkins - Philadelphia. 2008.

5. Borges C, Cunha G, Monteiro-Grillo I, Vaz P, Teixeira N. Comparison of different breast planning techniques and algorithms for radiation therapy treatment. Phys. Medica. 2014;30:160-170, doi:10.1016/j.ejmp.2013.04.006

6. ICRU. International commission on radiation units and measurements. 1989. Tissue substitutes in radiation dosimetry and measurement - ICRU REPORT 44. Maryland - United States

7. ISP. International Specialty Products. Gafchromic self-developing dosimetry films |EBT2 |EBT 3 | Cyberknife | HD-V2 | MD-V3 | RTQA2 Ashland Inc - ISP. 2014. Available at: www.ashland.com. Accessed 19 May 2014.

8. Chair ANR et. al. Radiochromic Film Dosimetry. 1998Nov;25(1):2093-2115, doi: 00942405/98/25(11)/2093/23/ $\$ 15.00$

9. Maia M. Fantoma antropomórfico antropométrico de tórax Para fins de Radioproteção e dosimetria. 2004. Dissertação, Universidade Federal de Minas Gerais, Belo Horizonte.

10. Schettini MP, Maia M, Campos TPR. The development of an anthropomorphic and anthropometric thorax female phantom for experimental radiodosimentry. International Journal of Low Radiation. 2007;4:124-135.

11. Nogueira LB. Síntese, caracterização e dosimetria de sementes radioativas de Ho e HoZr para tratamento de câncer de mama. 2012. Tese, Universidade Federal de Minas Gerais, Belo Horizonte.

12. Devic S, Seuntjens J, Hegyi G, Podgorsak EB, Soares CG, Kirov AS, Ali I, Williamson JF, Elizondo A. Dosimetric properties of improved GafChromic films for seven different digitizers. Med Phys. 2004:31:2392-2401, doi:10.1118/1.1776691

13. Devic S, Seuntjens J, Sham E, Podgorsak EB, Schmidtlein CR, Kirov AS, Soares CG. Precise radiochromic film dosimetry using a flat-bed document scanner. Medical physics. 2005, doi:10.1118/1.1929253

14. Thompson L, Dias HG, Campos TPR. Dosimetry in brain tumor phantom at 15 MV 3D conformal radiation therapy. Radiat Oncol. 2013;8:168, doi:10.1186/1748-717X-8-168

15. Image Processing And Analysis In Java- ImageJ. 2015. Available at: http://imagej.nih.gov/ij/. Accessed 19 May 2015.

16. Butson MJ, Yu PKN, Cheung T, Metcalfeb P. Radiochromic film for medical radiation dosimetry. Mater Sci Eng. 2003;41:61-120, doi: 10.1016/S0927-796X(03)00034-2

17. BIPM, IEC, IFCC, ILAC, ISO, IUPAC, IUPAP and OIML. Guide to the Expression of Uncertainty in Measurement JCGM 2008;100: GUM 1995 with minor corrections.

18. Chiu-Tsao ST, Chan MF. Photon beam dosimetry in the superficial buildup region using radiochromic EBT film stack. Med Phys. 2009;36:2074-2083, doi:10.1118/1.3125134

19. ORIGINLAB: Origin and originPro - data analysis and graphing - origin. 2015. Available at:http://www.originlab.com/. Accessed 19 May 2015

20. Soares CG. Radiochromic film dosimetry. Radiation Mearurements. 2007;41:S100-S116, doi: 10.1016/j.radmeas.2007.01.007

21. ISP. International Speciality Products. Gafchromic EBT2 - self-developing film for radiotheraphy dosimetry. New Jersey: ISP, 2010.

22. Aldelaijan S. et al. Evaluation of EBT-2 model GAFCHROMIC ${ }^{\text {TM }}$ film performance in water. Med Phys. 2010;37:3687, doi: 10.1118/1.3455713

23. Khan Faiz M. The Physics of Radiation Therapy. Lippincott Williams \& Wilkins, ed. 3 Philadelphia. 2003. 
24. Nogueira LB, Silva HLL, De Campos, T.P.R. Experimental dosimetry in conformal breast teletherapy compared with the planning system. Appl Radiat Isot. 2015;97:93-100, doi:10.1016/j.apradiso.2014.12.022.

25. Huet C, Dagois S, Derreumaux S, Trompier F, Chenaf C, Robbes I. Characterization and optimization of EBT2 radiochromic films dosimetry system for precise measurements of output factors in small fields used in radiotherapy. Radiat Meas. 2012;47:40-49, doi:10.1016/j.radmeas.2011.10.020 